\title{
The Modeling of Nitrogen Mass Transport in CoCr Alloys
}

\author{
*Akvilè Petraitienè \\ Aleksandras Stulginskis University, Center of Mathematics, Physics and Information Technologies, \\ Studentų 11, LT-53361 Akademija, Lithuania
}

\begin{abstract}
The kinetics of plasma nitriding of $\mathrm{CoCr}$ alloy below temperatures of nitrides formation and mechanisms of nitrogen penetration are analyzed by proposed kinetic modeling in this article. Proposed nitrogen diffusion model is based on the trapping - detrapping (TD) model and developed taking into account the effect of the concentration dependent diffusivity of nitrogen, nitrogen adsorption on the surface of alloy and surface swelling process. The model indicates the influence of chromium atoms to nitrogen atoms diffusivity. The model consists of time and depth dependent diffusion, which is described by a partial differential equation, and it is solved by using Crank - Nicolson finite difference method. By fitting of experimental nitrogen depth profiles, it is shown that nitrogen diffusion coefficient varies with nitrogen concentration according to Einstein-Smoluchowski relation. Nitrogen depth profiles in plasma nitrided medical grade $\mathrm{CoCr}$ alloy (ISO $5831-12$ ) at $T=400{ }^{\circ} \mathrm{C}$ for 1,4 and 20 hours calculated on the basis of this model are in good agreement with experimental nitrogen profiles. Furthermore, the swelling process is showed and analyzed, derived the dependency of swelling rate on nitriding duration - the swelling rate is inversely proportional to the square root of nitriding duration. The obtained diffusion coefficient value and the swelling process rates satisfy the experimental data form Ref. The derived model explains physical processes during plasma nitriding and allows obtaining nitrogen depth profiles for any requisite nitriding duration.
\end{abstract}

Keywords: Crank - Nicolson method, kinetic modeling, CoCr plasma nitriding.

\section{Introduction}

Cobalt chromium alloys are widely used in medicine for the various applications including cardiovascular uses, prosthetic replacements, dentistry implants, because they satisfy the imposed requirements for biomaterials (Lutz \& Mändl, 2010). Biomaterials must satisfy the requirements such as biocompatibility and good mechanical properties like strength, durability, hardness, good technological properties, stable structure (Wang, Zhang \& Dong, 2010). CoCr alloys are characterized by good yield strength (448-1606 MPa), Young's modulus (210-253 $\mathrm{GPa})$ and low wear rates $\left(4-6 \cdot 10^{-8} \mathrm{mg} \cdot(\mathrm{Nm})^{-1}\right)$ (Wang, Huang \& Zhang, 2012). The biocompatibility of $\mathrm{CoCr}$ alloys is related to their good corrosion resistance in the physiological environment because of high chromium concentration $(26 \sim 30$ at. \%). These alloys have thin passive oxide film, mainly composed of $\mathrm{Cr} 2 \mathrm{O} 3$ with low content of Mo oxides. Oxide film acts as a barrier for corrosion processes (Wang, Huang \&
Zhang, 2012). However, CoCr alloys, used as medical implants, have several exploitation problems. The main problem is toxicity by wear debris and deficiency of biocompatibility with surrounding living tissues. The release of toxic ions such as $\mathrm{Co}, \mathrm{Cr}, \mathrm{Al}$, Ni or nanoparticles as a wear debris from implants to body can cause apoptosis or necrosis (Lutz \& Mändl, 2009). The toxic ions and nanoparticles from implants can migrate through the issue and over time by increasing their concentration may cause allergic reactions and osteolysis. On the other hand, the reactive chemical species in physiological environment $\mathrm{H}_{2} \mathrm{O}_{2}, \mathrm{O}_{2}^{-}$ , NO can chemically alter the surface of $\mathrm{CoCr}$ implant (Çelik et al., 2008). This leads to failure of implant. The increase of the surface hardness and a reduction of the wear rate are still needed to improve biocompatibility and lifetime of the $\mathrm{CoCr}$ implants (Öztürk, Türkan \& Eroğlu, 2006).

Surface treatment of $\mathrm{CoCr}$ alloys by changing the composition, structure, mechanical properties

* Corresponding Author's email: 
and thickening the native protective oxide layer can increase the wear resistance and reduce the possibility of implant failure (Lutz, Lehmann \& Mändl, 2008). Plasma assisted thermochemical surface treatments such as low-temperature plasma nitriding, nitrogen plasma immersion ion implantation, and nitrogen ion beam implantation are used for the purpose to improve wear, corrosion resistance and fatigue strength of CoCr alloys (Wang, Zhang \& Shen, 2010). Various experiments of nitriding by plasma immersion ion implantation show an increase of the surface hardness to 15 - $20 \mathrm{GPa}$ with a wear rate reduced by a factor of $10-100$. These improvements arise because of large (up to 35 at. $\% \mathrm{~N}$ ) and deep (up to $10 \mu \mathrm{m}$ ) content of inserted nitrogen into $\mathrm{CoCr}$ alloy. Modified surface layer is formed, which consists mainly of a metastable phase, known as supersaturated or expanded austenite $\gamma \mathrm{N}$ phase. However, hard and wear resistant surface layer ( $\gamma \mathrm{N}$ phase) is formed if surface treatments are conducted at temperatures below $400-450{ }^{\circ} \mathrm{C}$ (Ichiki et al., 2012). At higher temperatures the precipitations of chromium nitrides are formed (Pichon et. al., 2010). The formation of nitrides gives a depletion of chromium and lower corrosion resistance of the alloys by suppressing the formation of a $\mathrm{Cr} 2 \mathrm{O} 3$ surface oxide (Manova et al., 2011; Lutz et al., 2011). The formation of chromium nitrides is a thermally activated process, so the faster formation of $\mathrm{CrN}$ at higher temperatures implies the decrease of a mobile nitrogen concentration. It was found that diffusion activation energy differs for low and high process temperatures. At low temperatures, the diffusion activation energy is $1.0-1.1 \mathrm{eV}$, while at temperature above $400{ }^{\circ} \mathrm{C}$ the reduced diffusion activation energy of $0.4-0.7 \mathrm{eV}$ is observed (Wang, Huang \& Zhang, 2012; Çelik et al., 2008). This is explained by different phase transformation depending on temperature: expanded lattice is obtained below $400{ }^{\circ} \mathrm{C}$ and $\mathrm{CrN}$ formation is obtained above $400{ }^{\circ} \mathrm{C}$. For temperature range from $250{ }^{\circ} \mathrm{C}$ to $600^{\circ} \mathrm{C}$, diffusion coefficients vary from $10^{-14}$ to $10^{-10}$ $\mathrm{cm}^{2} \mathrm{~s}^{-1}$ (Çelik et al., 2008).

The diffusion coefficients for various $\mathrm{CoCr}$ alloys (ISO 5832-12, HS 188, L605) are $10^{-12}-10^{-11} \mathrm{~cm}^{2} \mathrm{~s}^{-1}$ at $400{ }^{\circ} \mathrm{C}$. Anomalous diffusion process and lattice expansion during nitriding process of $\mathrm{CoCr}$ alloys are similar to nitriding of austenitic stainless steels (ASS). Depth profiles of nitrogen both in $\mathrm{CoCr}$ and ASS are not coherent with a simple diffusionlimited incorporation (erfc shape). High nitrogen concentration on the surface slowly decreases in the layer and has a sharp decrease and a tail in a bulk. This phenomenon is usually considered by $\mathrm{Cr}$ traps and concentration dependent diffusion (Mändl et al., 2013; Öztürk et al., 2011; Okur, 2009).
The purpose of this work is to propose a model, which could quantitatively describe nitriding mechanisms and the nitrogen distribution in $\mathrm{CoCr}$ alloys during plasma nitriding process at nitriding temperatures around $400{ }^{\circ} \mathrm{C}$.

The model which will be applied for explanation of nitrogen mass transport in nitrided $\mathrm{CoCr}$ alloy in this article is named a "trapping - detrapping" model. This model consists of partial differential equations, which were decided to be solved by using Crank Nicolson method.

Crank - Nicolson method was developed by John Crank and Phyllis Nicolson in 1947 (Crank \& Nicolson, 1996). It is a finite difference method used for numerically solving the partial differential equations. This method is widely used in physics for solving diffusion (Tadjeran \& Meerschaert, 2007; Sweilam, Khader \& Mahdy, 2012), heat (Ekolin, 1991) or internal stress equations (Galdikas, Petraitiene \& Moskalioviene, 2015). This article will represent Crank - Nicolson finite difference method application for solving nitrogen transfer processes in $\mathrm{CoCr}$ alloy during plasma nitriding. This method is a good choice for solving the diffusion equation as it is unconditionally stable for both $1 \mathrm{D}$ and $2 \mathrm{D}$ applications. The authors (Crank \& Nicolson, 1996) have developed a satisfactory method of evaluating solutions of differential equations in which derivatives with respect to both depth and time are replaced in a particular way by finite difference ratios; the solution is carried out numerically, and the only limitation on the number of intervals in is that of time of solution. The time step value should be chosen sufficiently small in order to avoid instabilities or oscillations of the computed results (Harrison, 1996). The ratio of time and depth has to be small $(<0.5)$; otherwise, the code becomes unstable with the occurrence of oscillations (Moskalioviene \& Galdikas, 2012).

\section{Matherial and Methods}

The modeling

The model, applied in this article, for nitrogen distribution in plasma nitrided $\mathrm{CoCr}$ alloy, is named a trapping - detrapping model. This model is based on the theory that diffusion of nitrogen is decelerated by $\mathrm{Cr}$ atoms, which associate with $\mathrm{N}$ atoms for some time duration (Parascandola, Möler \& Williamson, 2000). This model was developed for nitrogen mass transfer in stainless steels (Möller et al., 2001), but according to the similarity of CoCr to stainless steel, the same model can be used for CoCr alloys. After some time duration the nitrogen can be detrapped with detrapping energy and freely diffuse in the bulk. The model also consists of nitrogen adsorbtion on the surface, concentration dependent diffusion and 


$$
\begin{aligned}
& \frac{\partial N_{d i f}(x, t)}{\partial t}=\frac{\partial D(N)}{\partial x} \cdot \frac{\partial N_{d i f}(x, t)}{\partial x}+D(N) \frac{\partial^{2} N_{d i f}(x, t)}{\partial x^{2}}-S(x, t)+ \\
& +\alpha \cdot j_{0}(x) \cdot\left(N_{o}-N_{d i f}(x, t)-N_{\text {trap }}(x, t)\right)+v_{s} \frac{\partial N_{d i f}(x, t)}{\partial x} \\
& \frac{\partial N_{\text {trap }}(x, t)}{\partial t}=S(x, t)=4 \pi R_{t} D(N) \cdot\left[N_{d i f}(x, t)\left(H_{t}-N_{\text {trap }}(x, t)\right)-N_{o} N_{\text {trap }}(x, t) e^{\frac{-E_{B}}{k_{B} T}}\right] \\
& +v_{s} \frac{\partial N_{\text {trap }}(x, t)}{\partial x} \\
& \frac{\partial N(x, t)}{\partial t}=\frac{\partial N_{d i f}(x, t)}{\partial t}+\frac{\partial N_{\text {trap }}(x, t)}{\partial t} \\
& i_{0}(x>0)=0
\end{aligned}
$$

where $N_{\text {dif }}$ - the amount of nitrogen, which diffuses in the bulk, $N_{\text {trap }}$ - the amount of nitrogen, which is in traps. $\alpha \cdot j_{0}(x) \cdot\left(N_{o}-N_{\text {dif }}(x, t)-N_{\text {trap }}(x, t)\right)$-adsorption term (Moskalioviene et al., 2011), $v_{s}$ - swelling rate. The (2) Eq. describes the nitrogen in the traps. $H_{t}$ - the concentration of $\mathrm{Cr}$ in CoCr alloy, $R_{t}$ - the lattice constant of $\mathrm{Cr}, E_{B}$ - nitrogen detrapping from $\mathrm{Cr}$ activation energy, $N_{0}$ - the concentration of host atoms. $k_{B}$ - Boltzmann constant, $T$ - temperature in $\mathrm{K}$. $j_{0}$ - flux of the nitrogen, $\alpha$ - the sticking coefficient of nitrogen to the surface atoms. The (4) equation describes the nitrogen adsorption on the surface of nitride alloy. It means that the term of adsorption is involved only on the first monolayer of the surface $(k=0)$. For deeper monolayer $(k>0)$, this term is equal to zero. The adsorption of the nitrogen is on process only on the surface.

swelling process. The final trapping - detrapping model equations are shown below:

According to the general diffusion theory, the diffusion coefficient in a concentration gradient depends on the local concentration of the diffusing element. Furthermore, in previous works (Galdikas \& Petraitiene, 2014) it was shown that diffusion coefficient depends on nitrogen concentration according to Einstein-Smoluchowski relation: $D(N)=\frac{R T L}{N}$, where $L$ is the Onsager coefficient, $N$ is the nitrogen concentration, $R$ and $T$ are the universal gas constant and temperature, respectively. The phenomenological diffusion coefficient $d_{\text {const }}=R T L$ is constant parameter in this model and $D(N)=\frac{d_{\text {const }}}{N}$ - the diffusion coefficient, dependent on nitrogen concentration.

The partial differential equations (1-3) can be solved by using Crank - Nicolson finite difference method. The nitrogen mass transfer is described by following equations after application of Crank Nicolson finite difference method:

On the surface (the first monolayer), $k=0$ :

$$
\begin{aligned}
& \frac{\partial N_{d i f}^{(0)}}{\partial t}=-\frac{D(N)^{(0)}}{h^{2}}\left(N_{d i f}^{(1)}-N_{d i f}^{(0)}\right)+\alpha \cdot j_{0}\left(N_{0}-N_{d i f}^{(0)}-N_{\text {trap }}^{(0)}\right)-S^{(0)}+\frac{D(N)^{(1)}-D(N)^{(0)}}{h^{2}} . \\
& \left(N_{d i f}^{(1)}-N_{d i f}^{(0)}\right)+\frac{v_{s}}{h} \cdot\left(N_{d i f}^{(1)}-N_{d i f}^{(0)}\right),
\end{aligned}
$$




$$
\frac{\partial N_{t r a p}^{(0)}}{\partial t}=S^{(0)}=4 \pi R_{t} D(N)^{(0)}\left[N_{d i f}^{(0)}\left(H_{t}-N_{\text {trap }}^{(0)}\right)-N_{0} N_{\text {trap }}^{(0)} e^{\frac{-E_{B}}{k_{B} T}}\right]+\frac{v_{s}}{h} \cdot\left(N_{\text {trap }}^{(1)}-N_{\text {trap }}^{(0)}\right)
$$

And for other monolayers, $k>0$

$$
\begin{aligned}
& \frac{\partial N_{d i f}^{(k)}}{\partial t}=\frac{D(N)^{(k)}}{h^{2}}\left(N_{d i f}^{(k+1)}-2 N_{d i f}^{(k)}+N_{d i f}^{(k-1)}\right)-S^{(k)}+\frac{\left(D(N)^{(k+1)}-D(N)^{(k)}\right)}{h^{2}} \cdot\left(N_{d i f}^{(k+1)}-N_{d i f}^{(k)}\right) \\
& +\frac{v_{s}}{h} \cdot\left(N_{d i f}^{(k+1)}-N_{d i f}^{(k)}\right), \\
& \frac{\partial N_{\text {trap }}^{(k)}}{\partial t}=S^{(k)}=4 \pi R_{t} D(N)^{(k)}\left[N_{d i f}^{(k)}\left(H_{t}-N_{\text {trap }}^{(k)}\right)-N_{0} N_{\text {trap }}^{(k)} e^{\frac{-E_{B}}{k_{B} T}}\right]+\frac{v_{s}}{h} \cdot\left(N_{\text {trap }}^{(k+1)}-N_{\text {trap }}^{(k)}\right)
\end{aligned}
$$

where $\mathrm{h}$ is the thickness of one monolayer. The eqs. (5) - (8) are integrated over the time interval from to The time differences' value is s. The limitations of the model are the following: the model can be applied only on the small process temperatures - until $450{ }^{\circ} \mathrm{C}$, because higher temperatures lead to the formation of $\mathrm{Cr}$ nitrides (Wang et. al, 2012). The nitriding process duration (more than $20 \mathrm{~h}$ ) and the relative concentration of nitrogen cannot exceed 40 at. \% on the surface of nitrided alloy (Okur, 2009). The model does not involve such processes on the surface which can occur - sputtering on the surface and defect formation due to high energy ion bombardment.

By solving the above equations (Eqs. (5) - (8)) for $N_{d i f}$ and $N_{\text {trap }}$ one can easily calculate the time evolution of a depth profile.

\section{Materials}

To analyze the kinetics of nitriding process and verify modified trapping-detrapping model, the experimental nitrogen depth profiles were fitted by model equations. The experimental results (Figure1 experimental profiles) are taken from References (Okur, 2009; Öztürk, Fidan \& Mändl, 2013) where plasma nitriding of a medical grade wrought low carbon cobalt-chromium-molybdenum (CoCrMo) alloy (ISO 5832-12) samples were analyzed. The $\mathrm{CoCr}$ alloy samples were exposed to the following plasma nitriding conditions (Okur, 2009): (1) a gas composition of $60 \% \mathrm{~N}_{2}+40 \% \mathrm{H}_{2}$; (2) a working pressure of $\sim 60$ mTorr and RF power of $700 \mathrm{~W}$; (3) a substrate temperature of $400^{\circ} \mathrm{C}$ (to avoid chromium nitride precipitation in the surface treated layer), and the nitriding duration was $1 \mathrm{~h}, 4 \mathrm{~h}$ and $20 \mathrm{~h}$.

\section{Results}

The nitrogen depth profiles in $\mathrm{CoCr}$ (Figure 1) were calculated by Eqs. (5) - (8). The developer kinetic model equations are solved by using Crank -

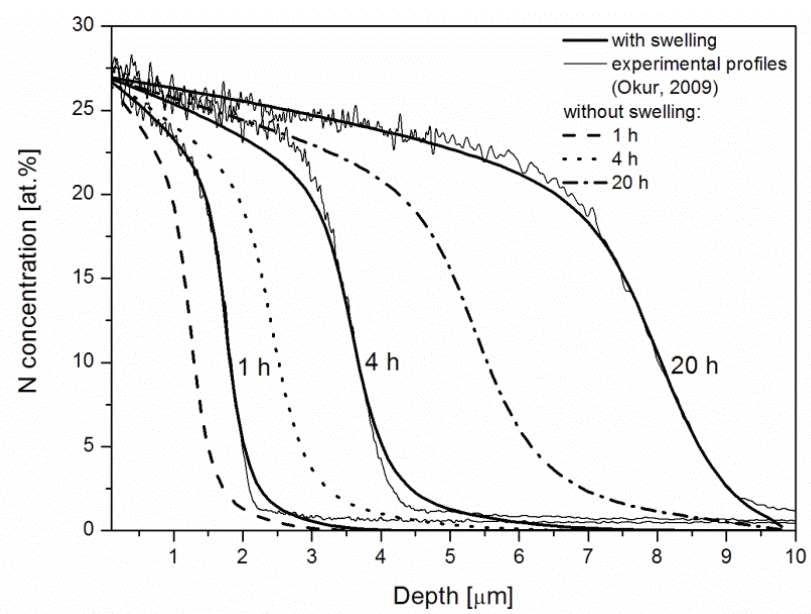

Figure 1. Experimental profiles (Okur, 2009) and calculated (Eqs. (6) - (9)) nitrogen depth profiles (solid lines) in nitrided $\mathrm{CoCr}$ alloy at $400{ }^{\circ} \mathrm{C}$ for different nitriding durations $1,4,20 \mathrm{~h}$.

Dash lines - calculations without swelling. 
Nicholson finite difference method. For the calculations, a computer program was written by using Borland Delphi 7 software package.

The $d_{\text {const }}, E_{B}$ and $v_{s}$ are undefined model parameters and in this work were extracted by fitting the experimental curves of nitrogen depth profiles. The other model parameters were defined either by the experiment (Öztürk et. al., 2011) or from literature data: $E_{A}=1,1 \mathrm{eV}$ (Lutz, Lehmann \& Mändl, 2008); $R_{t}=0,38 \times 10^{-9} \mathrm{~m}$ (Martinavičius et al., 2009); $N_{0}=$ $8,8 \times 10^{16} \mathrm{~m}^{-3}$ (Mishler, Munoz, 2013); $H_{t}=2,64 \times 10^{16}$ $\mathrm{m}^{-3}$. The calculations were performed by varying free model parameters $v_{s}, d_{\text {const }}$ and $E_{B}$ values in order to get the best fit. According to the similarity of the $\mathrm{CoCr}$ alloys to stainless steels, the varying free model parameters were chosen similar to the ones for stainless steel from References (Abrasonis et. al., 2005, Moskalioviene et. al., 2011, Stinville et al., 2011). The detrapping energy varied from $0,3 \mathrm{eV}$ to $0,4 \mathrm{eV}$ by step of $0,1 \mathrm{eV}$, the phenomenological diffusion coefficien varied from 1 to $3 \times 10^{-15} \mathrm{~m}^{2} \mathrm{~s}^{-1}$ by step of $0,1 \times 10^{-15} \mathrm{~m}^{2} \mathrm{~s}^{-1}$ and the swelling rate changed in the interval from 0,05 to $0,03 \mu \mathrm{m} \cdot \mathrm{h}^{-1}$ by step of $0,001 \mu \mathrm{m} \cdot \mathrm{h}^{-1}$. The best fit was chosen by visual equivalent of experimental distribution of nitrogen depth profile.

Fitting results are presented in Figure 1 together with the experimental nitrogen depth profiles. All three nitrogen depth profiles (for $1 \mathrm{~h}, 4 \mathrm{~h}$ and $20 \mathrm{~h}$ of nitriding) were calculated with the same $d_{\text {const }}$ $=2,0 \times 10^{-15} \mathrm{~m}^{2} / \mathrm{s}$ and $E_{B}=0,35 \mathrm{eV}$ values. The concentration dependent diffusion coefficient $D(N)$ values, which were used to calculate nitrogen profiles (Figure 1) are plotted in Figure 2.

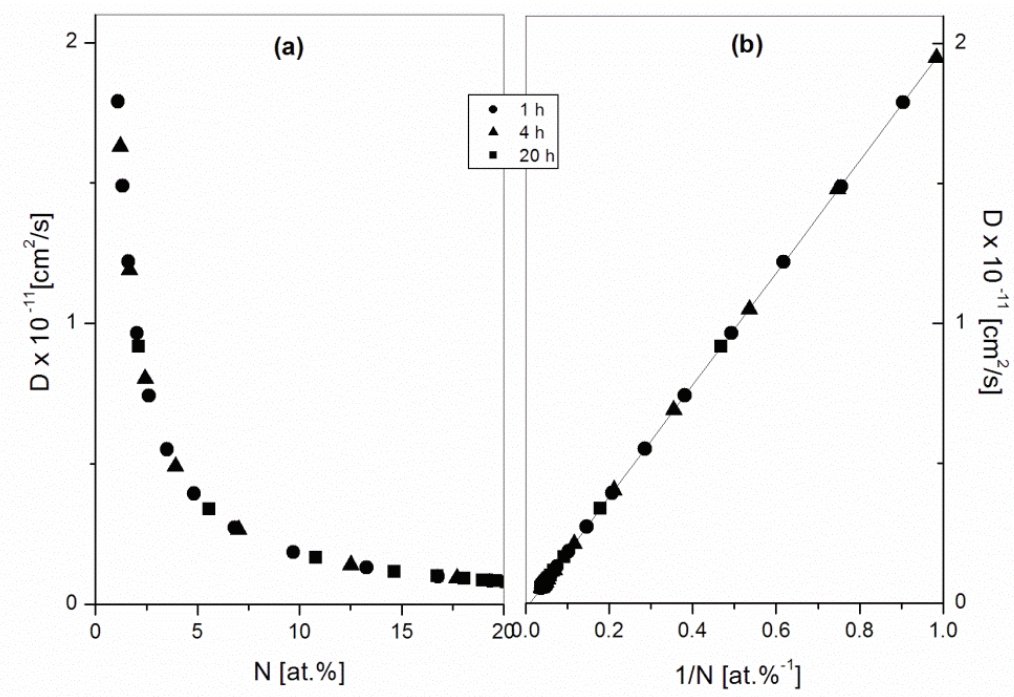

Figure 2. The diffusion coefficient values plotted as functions of (a) $N$ and (b) $1 / N$.

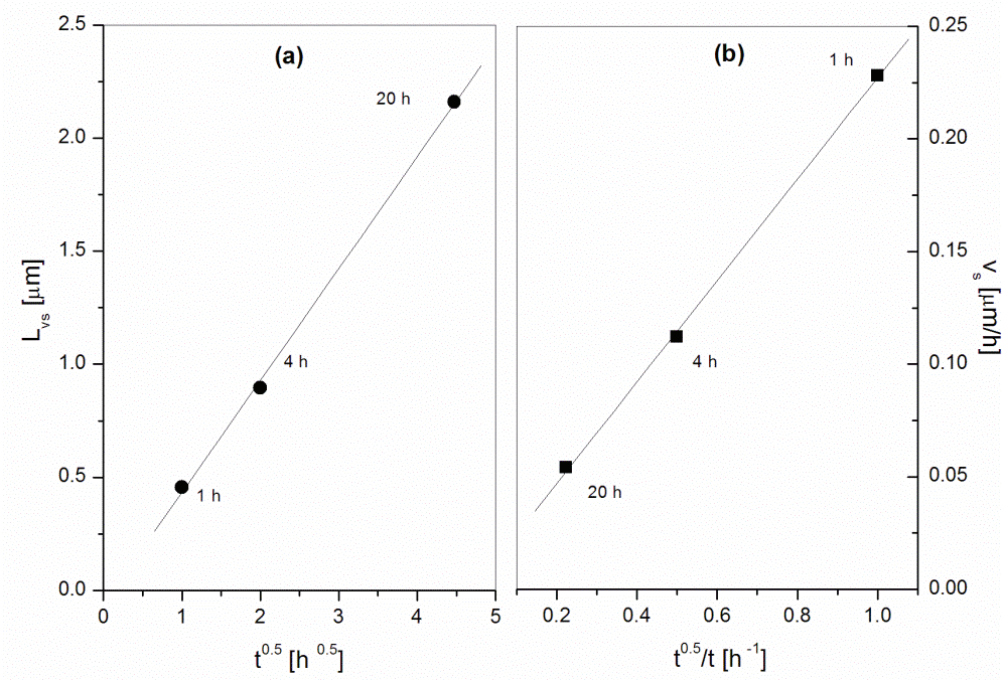

Figure 3. The dependencies of swelling thickness (a) and swelling rate (b) on nitriding time. 
During nitriding the process of swelling takes place (Stinville, et. al., 2011). In order to keep $d_{\text {const }}$ coefficient as a constant and to get best fit for experimental results, it was necessary to take account of the swelling process. The calculated profiles without swelling (by Eqs. (5) $-(8)$ with $v_{s}=0$ ) are plotted in Figure 1. It is seen that the calculated results disagree with the experiment. According to the literature (Stinville et. al., 2011; Chollet et. al., 2013), the swelling rate $v_{s}$ is not constant, it is dependent on the nitriding time as a function $v_{s} \approx f(1 / \sqrt{t})$. Obtained from the fitting $v_{s}$ values $\left(0,228 \mu \mathrm{m} \cdot \mathrm{h}^{-1}, 0,122 \mu \mathrm{m} \cdot \mathrm{h}^{-1}\right.$ and $0,054 \mu \mathrm{m} \cdot \mathrm{h}^{-1}$ for 1,4 and $20 \mathrm{~h}$ nitriding durations, respectively) are different for different nitriding durations and are plotted in Figure 3 a.

\section{Discussion}

The concentration of nitrogen in the alloy is dependent on the nitriding duration - with the increase of nitriding time the concentration of nitrogen increases (Figure 1), and it means that diffusion coefficient $D(N)$ decreases with the increase of nitrogen concentration (Figure 2a). According to the Einstein - Smoluchowski, the diffusion coefficient is inversely proportional to the nitrogen concentration (Figure 2b). Further, it is seen (Figure 2) that all values of diffusion coefficient for different nitriding time samples $(1 \mathrm{~h}, 4 \mathrm{~h}$ and $20 \mathrm{~h})$ lie in one line as function of $D \sim(1 / N)$. It is important to note that obtained from fitting $d_{\text {const }}$ value is the same for different samples with different nitriding duration and correlates with diffusion coefficient values for similar $\mathrm{CoCr}$ alloys which were reported in Ref. (Okur, 2009). The extracting of value $d_{\text {const }}$ from experimental fitting of this model allows calculating nitrogen concentration depth profiles for any nitriding duration.

The values of swelling thickness obtained by fitting show linear increase with the square root of the nitriding time (Figure $3 \mathrm{~b}$ ). The same linear dependency on square root nitriding time is experimentally obtained for stainless steels (Stinville, et. al., 2011; Chollet, et. al., 2013). From the above analysis follows that the main processes which occur during plasma nitriding of $\mathrm{CoCr}$ alloys below temperatures of nitrides formation are the trapping detrapping, concentration dependent diffusion and also swelling. Including those processes into kinetic differential equations gives a good comparison between the numerical prediction and experimental results.

\section{Conclusion}

The "trapping - detrapping" model was applied for analysis of nitrogen mass transfer in $\mathrm{CoCr}$ alloys. The partial differential equations of this model were solved by using Crank - Nicolson finite difference method. During experiments with this model, a conclusion to involve nitrogen concentration dependent diffusion coefficient of nitrogen and alloy's swelling processes was made. These changes let us reduce the number of variable parameters of model dependent on nitriding duration and leave only one variable parameter swelling rate, which depends on the nitriding duration $v_{s}=f(\sqrt{t})$. During experiment it was found that nitrogen detrapping energy for ISO $5831-12$ alloy is $0,35 \mathrm{eV}$. Phenomenological diffusion coefficient for ISO $5831-12$ alloy is $2 \cdot 10^{-15} \mathrm{~m}^{2} \mathrm{~s}^{-1}$ at $400{ }^{\circ} \mathrm{C}$ temperature and the swelling rates: $v_{s .1 h}=0,2286$ $\mu \mathrm{m} \cdot \mathrm{h}^{-1}, \quad v_{s .4 h}=0,1249 \mu \mathrm{m} \cdot \mathrm{h}^{-1} \quad$ and $\quad v_{s . D h}=0,0624$ $\left.\mu \mathrm{m} \cdot \mathrm{h}^{-1}\right)$.

\section{References:}

1. Abrasonis, G., Riverie, J. P., Templier, C., Declemy,A., Pranevicius, L., \& Milhet, X. (2005). Ion beam nitriding of single and polycrystalline austenitic stainless steel. Applied Physics, 97, 083531-10. DOI: 10.1063/1.1863455.

2. Çelik, A., Bayrak, Ö., Alsaran, A., Kaymaz, İ., \& Yetim, A.F. (2008). Effects of plasma nitriding on mechanical and tribological properties of CoCrMo alloy. Surface \& Coatings Technology, 202(11), 2433-2438. DOI: 10.1016/j. surfcoat.2007.08.030.

3. Chollet, S., Pichon, L., Cormier, J., Dubois, J.B., Villechaise, P., Drouet, M., Declemy, A. \& Templier, C. (2013). Plasma assisted nitriding of $\mathrm{Ni}$ - based superalloys with various microstructures. Surface and Coatings Technology, 235, 318 - 325. DOI: 10.1016/j. surfcoat.2013.07.060.

4. Crank, J., \& Nicolson, P. (1996). A Practical Method for Numerical Evaluation of Solutions of Partial Differential Equations of the Heat Conduction Type. Advances in Computational Mathematics, 6(1), 207 - 216. DOI: 10.1007/ BF02127704.

5. Ekolin, G. (1991). Finite difference methods for a nonlocal boundary value problem for the heat equation. BIT Numerical Mathematic, 31(2), 245 - 261. DOI: 10.1007/BF01931285.

6. Galdikas, A., Petraitienè, A., \& Moskaliovienè, T. (2015). Internal stress assisted nitrogen 
diffusion in plasma nitrided medical CoCr alloys. Vacuum, 119(1), 233 - 238. DOI: 10.1016/j. vacuum.2015.05.029.

7. Galdikas, A. \& Petraitiene, A. (2014). Modeling of nitrogen penetration in medical grade $\mathrm{CoCrMo}$ alloy during plasma nitriding. Materials Science (Medžiagotyra), 20(1), 25-30.

8. Harrison, P. (1996). Numerical solution to the general one - dimensional diffusion equation in semiconductor heterostructures. Basic solid state physics, 197(1), 81 - 90. DOI: 10.1002 / pssb.2221970113.

9. Ichiki, R., Nagamatsu, H., Yasumatsu, Y., Iwao, T., Akamine, S., \& Kanazawa, S. (2012). Nitriding of steel surface by spraying pulsed - arc plasma jet under atmospheric pressure. Materials Letters, 71, 134 - 136. DOI: 10.1016/j. matlet.2011.12.054.

10. Lutz, J. \& Mändl, S. (2010). Reduced tribocorrosion of $\mathrm{CoCr}$ alloys in simulated body fluid after nitrogen insertion. Surface \& Coatings Technology, 204(18-19), 3043 - 3046. DOI: 10.1016/j.surfcoat.2010.01.048.

11. Lutz, J., \& Mändl, S. (2009). Effect of ion energy and chemistry on layer growth processes during nitriding of $\mathrm{CoCr}$ alloys. Nuclear Instruments and Methods in Physics Research B, 267(18-19), 1522-1525. DOI: 10.1016/j.nimb.2009.01.083.

12. Lutz, J., Lehmann, A. \& Mändl, S. (2008). Nitrogen diffusion in medical CoCrNiW alloys after plasma immersion ion implantation. Surface \& Coatings Technology, 202(15), 374737534. DOI: 10.1016/j.surfcoat.2008.01.020.

13. Lutz, J., Díaz, C., García, J. A., Blawert, C., \& Mändl, S. (2011). Corrosion behavior of medical $\mathrm{CoCr}$ alloy after nitrogen plasma immersion ion implantation. Surface \& Coatings Technology, 205(8-9), 3043-3049. DOI: 10.1016/j. surfcoat.2010.11.017.

14. Manova, D., Lutz J., Gerlach, J.W., Neumann, H., \& Mändl, S. (2011). Relation between lattice expansion and nitrogen content in expanded phase in austenitic stainless steel and CoCr alloys. Surface \& Coatings Technology, 205(2), S290S293. DOI: 10.1016/j.surfcoat.2010.12.046.

15. Mändl, S., Díaz, C., Gerlach, J.W., \& García, J.A. (2013). Near surface analysis of duplex PII treated $\mathrm{CoCr}$ alloys. Nuclear Instruments and Methods in Physics Research B, 307, 305-309. DOI: 10.1016/j.nimb.2012.11.052.

16. Martinavičius, A., Abrasonis, G., Möller, W., Templier, L., Rivière, J. P., Declémy, A. \& Chumlyakov, Y. (2009). Anisotropic ion- enhanced diffusion during ion nitriding of single crystalline austenitic stainless steel. Journal of applied physics, 105, 093502-7. DOI: 10.1063/1.3120912.

17. Mischler, S. \& Munoz, A. I. (2013). Wear of CoCrMo alloys used in metal-on-metal hip joints: a tribocorrosion appraisal. Wear, 297(1), 1081-1094. DOI: 10.1016/j.wear.2012.11.061.

18. Moskalioviene, T., Galdikas, A., Rivière, J. P., \& Pichon, L. (2011). Modeling of nitrogen penetration in polycrystalline AISI $316 \mathrm{~L}$ austenitic stainless steel during plasma nitriding. Surface \& Coatings Technology, 205(10), 33013306. DOI: 10.1016/j.surfcoat.2010.11.060.

19. Moskalioviene, T. \& Galdikas, A. (2012). Stress induced and concentration dependent diffusion of nitrogen in plasma nitride austenitic stainless steel. Vacuum, 86(10), 1552-1557. DOI: 10.1016/j.vacuum.2012.03.026.

20. Möller, W., Parascandola, S., Telbizova, T., Günzel, R., \& Richter, E. (2001). Surface processes and diffusion mechanisms of ion nitriding of stainless steel and aluminum. Surface and Coatings Technology. 136(1-3), 73-79. DOI: 10.1016/S0257-8972(00)01015-X.

21. Okur, S. (2009). Structural compositional and mechanical characterization of plasma nitrited CoCrMo alloy. Master of Science Thesis in Physics, İzmir Institute of Technology.

22. Öztürk, O., Fidan, M., \& Mändl, S. (2013). MFM imaging of expanded austenite formed on 304 SS and CoCrMo alloys. Surface and Coatings Technology, 256(15), 15 - 22. DOI: 10.1016/j. surfcoat.2013.11.045.

23. Öztür, O., Türkan, U., \& Eroğlu, A.E. (2006). Metal ion release from nitrogen ion implanted CoCrMo orthopedic implant material. Surface \& Coatings Technology, 200(20-21), 5687-5697. DOI: 10.1016/j.surfcoat.2005.08.113.

24. Öztürk, O., Okur, S., Pichon, L., Liedke, M. O., \& Riviere, J. P. (2011). Magnetic layer formation on plasma nitrided CoCrMo alloy. Surface \& Coating Technology, 205, 280-285. DOI: 10.1016/j.surfcoat.2011.01.047.

25. Parascandola, S., Möler, W., \& Williamson, D. L. (2000). The Nitrogen Transport in Austenitic Stainless Steel at Moderate Temperatures. Applied Physics Letters, 76(16), 2194 - 2196. DOI: $10.1063 / 1.126294$.

26. Pichon, L., Okur, S., Özturk, O., Riviere, J.P., \& Drouet, M. (2010). CoCrMo alloy treated by floating potential plasma assisted nitriding and plasma based ion implantation: Influence of 
the hydrogen content and of the ion energy on the nitrogen incorporation. Surface \& Coatings Technology, 204(18 - 19), 2913-2918. DOI: 10.1016/j.surfcoat.2010.01.050.

27. Stinville, J. C., Templier, C., Villechaise, P. \& Pichon, L. (2011). Swelling of 316L austenitic stainless steel induced by plasma nitriding. Journal of Material Science, 46(16), 5503-5511. DOI: $10.1007 / \mathrm{s} 10853-011-5494-8$.

28. Sweilam, N. H., Khader, M. M., \& Mahdy, A. M. S. (2012). Crank - Nicolson finite difference method for solving time - fractional diffusion equation. Journal of Fractional Calculus and Applications. 2 (2), 1 - 9.

29. Tadjeran, C., \& Meerschaert, M. M. (2007). A second-order accurate numerical method for the two - dimensional fractional diffusion equation. Journal of Computational Physics. 220(2), 813 823. DOI: $10.1016 /$ j.jcp.2006.05.030.
30. Wang, Q., Zhang, L. \& Dong, J. (2010). Effects of Plasma Nitriding on Microstructure and Tribological Properties of CoCrMo Alloy Implant Materials. Journal of Bionic Engineering, 7(4), 337-344. DOI:10.1016/ S1672-6529(10)60265-X.

31. Wang, Q., Huang, C., \& Zhang, L. (2012). Microstructure and Tribological Properties of Plasma Nitriding Cast CoCrMo Alloy. Juornal of Material Science Technology, 28(1), 60-66. DOI: 10.1016/S1005-0302(12)60024-3.

32. Wang, Q., Zhang, L., Shen, H. (2010). Microstructure analysis of plasma nitrided cast/ forged CoCrMo alloys. Surface \& Coatings Technology, 205(7), 2654-2660. DOI: 10.1016/j. surfcoat.2010.10.031.

\section{Acknowledgements}

This research was done in the framework of the Nordplus Higher Education 2016 project NPHE-2016/10342 "Raising awareness about the role of math skills in building specialists' competence for the sustainable development of society”. 